\title{
OPEN SOURCE TECHNOLOGY AS AN OPTION FOR AN ALBANIAN UNIVERSITY WITH NO ONLINE PLATFORM: CAN IT BE USED TO IMPROVE LEARNING?
}

\author{
Gerda Sula ${ }^{1}$
}

\begin{abstract}
Online platforms are a worthy opportunity for extended learning, peer collaboration, and joint efforts outside the university classroom. However, in order to offer such a pedagogical tool, the online environment needs to be designed for teachers and students alike. The University of Tirana does not offer such platforms and hence, this study explores whether other open source platforms could be used to fulfill the aims and objectives of the subjects offered at this university. The results of this research, comparing two groups of students' performance of the Curriculum Design class, one with no online platform access, and the other with platform access, showed that students' understanding was heightened significantly in the group with online access. In this paper, the benefits of such opportunities in developing countries with no technological platform are discussed. Furthermore, recommendations for the researcher or teacher are shared regarding the planning and management of resources, such as time, discussion, and conclusions for others interested in embarking on the same path.
\end{abstract}

UDC Classification: 378, DOI: http://dx.doi.org/10.12955/cbup.v4.849

Keywords: developing countries, higher education, open source.

\section{Introduction}

Often. it seems, that higher education has lost the "war" against online tools, with students staring at their screens while the lecturer is trying to convey an important message. This scenario is not an alien view to many teachers standing in front of students and such a "fight" is not new by any means. New technologies have been scoffed at, feared, and kept outside teaching for as long as one can remember in the public school systems. History has included the fountain pen replacing the quill, the ballpoint pen replacing the fountain pen, and the calculator replacing manual calculation (Probable Quotes from History, Fall, 1978). Such dialectics between traditional and safe pedagogical tools, which can be uninspiring for the students, and new and risky, but enthralling and intriguing for students, will continue to coexist (Raina and Khatri, 2015). The latest strategy is based more on the constructivist approach to learning, that is, one learns more effectively through social interaction with the teacher, the peers, and others, than learning alone (Garrison and Richardson, 2009). Garrison and Archer (2000) noted "construction of meaning may result from individual critical reflection but ideas are generated and knowledge constructed through the collaborative and confirmatory process of sustained dialogue within a critical community of learners" (p. 91).

\section{Purpose of Study}

Rather than considering the internet a major enemy and attempting to annihilate it, one could circumvent the issues and use the internet for teaching purposes. Based on the literature (Raina and Khatri, 2015; Jonasssen, Mayes, and MacHeese, 1993), there are technology platforms for continued learning outside the university and these have been helpful for students to improve their grasp of the nuances of learning and to have an opportunity to co-learn with "more knowledgeable peers" and learn in the zone of proximal development (Vygotsky, 1929). Thus, the purpose of this study is to investigate online platforms for extending teaching. The scope of the study involves the University of Tirana, Albania, where classes were typically taught, without the support of online platforms. This study examined whether learning needs could be complimented with out-of-class, online learning approaches, but without access to specific online platforms available to both students and teachers at the university level during the academic year of 2014-2015.

\section{Methodology}

To analyze the effects of the online compliment to the face-to face course of Masters study, a process of studying a real school situation from the viewpoint of the practitioner. Such demand is fulfilled by

\footnotetext{
${ }^{1}$ Gerda Sula, University of Tirana , Tirana, Albania, gerda.sula@unitir.edu.al
} 
the action research design, in which a real classroom situation is followed so that the quality of learning and instruction is improved (Johnson, 2002). The steps needed to complete an action research are: (1) define the area of exploration, which in our case was to understand whether the open source online tools could be used for the benefit of student learning; (2) specify the data collection; (3) data collection and analysis; (4) explore how to use and apply the data, planning an action based on the findings; and (5) report writing (Johnson, 2002).

The author was the teacher in the courses offered and explored in this research. Two groups of students were sampled in the research: Group 1 involved students from the Master of Sciences in Teaching of Social Sciences $(\mathrm{N}=38)$ using the online tool and Group 2: students from the Master of Sciences in Teaching of Foreign Languages $(\mathrm{N}=50)$ using only the face-to-face approach. Both groups had no instructed access to the online tool and were attending the same compulsory subject: Curriculum Design and Development, with equal weight credits and the same teacher.

The research involved use of a Facebook (FB) community page for simplicity of setup, student familiarity with Facebook (91\% of students had a FB page, with other social media not as popular), ease of access, and the lack of knowledge of other forms available. The group 1 students had to write a memo of reflection as a paragraph of 100-150 words, and a pictogram, a video, and music in which they could share an insight, ask probing questions, and share life experiences that were compliant or completely divergent from the viewpoint of the author. In addition, they were encouraged to comment or reply to their peers' memo of reflection. This was worth $10 \%$ of their final grade for the subject.

To obtain data for the main research point, information was collected from: 1) a questionnaire; 2) student focus groups; 3 ) data of students' performance; and 4. teacher self-reflection, as detailed in the following:

1. the questionnaire - an eighteen-item questionnaire was developed to measure (a) the level of understanding of the aims and goals of the subject by the students; (2) reported reading time (how many hours in total), and extension of reading time for this subject (regularity); (3) perception of students on their involvement in the subject; and (4) student perception regarding their learning. The questionnaire was administered to all students at the same period and received $100 \%$ response rate.

2. Student focus group - ten students from the class with online access were interviewed regarding their experience, using a semi-structured interview questionnaire.

3. Data collection - (a) student attendance at lectures, as a non-compulsory activity at the University of Tirana, which would show whether there was a difference in the interest of two groups of students; and (b) students' cumulative grades.

4. Teacher motivation - a log reporting on teacher motivation, teaching hours spent in planning, developing the platform, and interacting with students outside the office hours.

\section{Results}

The data showed a large difference in percentage of improvement between the two groups. With the online group, continuous reading rather than a cramming of information at the end of the academic year (28\% weekly for the group 1 vs. $13 \%$ weekly for the group 2 ) and the time students reported in weekly reading was increased (83 min. for the group 1 vs. $62 \mathrm{~min}$. for the group 2). Students' attendance was significantly increased (78\% for the group 1 vs. $54 \%$ for the group 2 ). One set of data of relevance to the teacher was that the students in group 1 were much more apt at articulating the aims of the course. For this, $45 \%$ of the group 1 could articulate three goals, while no student in the group 2 could articulate more than two goals regarding this course. There was an increase of students' perception in that they worked "harder" with the online tool than without it (for the group 1 students: $28 \%$ responded working much harder; $44 \%$ working harder; $11 \%$ working equally hard; $12 \%$ less hard; and 5\% no response), and were better motivated (14\% higher motivation). Group 1 students reported they learnt more because of access to the tool (89\% learning more; $9 \%$ they are learning much more; and $2 \%$ no response).

The teacher log showed increased teacher motivation when preparing for group 1, but also increased time spent on the online page, and even addiction and some level of obsession in reading comments. 
The latter, regarding the use of time resources, needs to be considered well in advance when designing and using such tools.

\section{Conclusion}

The online learning platform using open source created scope for greater interaction, not merely communication. Students in group 1 had time to reflect upon their thinking and compare this with their peers and moreover, could synthetize a higher-level cognitive learning objective, which is not easily tackled through ex-cathedra teaching of group 2 students. Because the students in group 1 had to reflect beforehand, they were more eager to participate during lectures, and the lecturer could easily probe students regarding content delivery and revision. Thus, the identification of important points was much more thorough and consistent for group 1. The study task in group 1 also allowed for a more meaningful horizontal (student to student) collaboration. In group 2, the students wrote a memo of reflection, but would only share it with the teacher (vertical sharing). As the group 1 students would comment on their peers' thinking even before the class, their thinking would become deeper and more meaningful. Moreover, the task of the lecturer to prepare for the class was eased with the online tool, as the understanding of thinking patterns was clearer, and the most important issues to be tackled and how to go about delivering a meaningful lecture to this group of students was more evident, as opposed to preparing for an anonymous group. The task of accessing an online tool also allowed for a sense of cohort. Using a formative and summative assessment was also helpful. In addition, students of group 1 shared that they felt more in control of their own learning as they could return to their own or other's memo of reflection, which they appreciated as an added support to prepare for exams. The role of the lecturer was diversified as well, as it allowed scope for providing more guidance rather than merely teaching. Furthermore, students became part of the teaching process as they developed knowledge and undertook thorough research, and this added to the body of knowledge available.

However, should one decide to design and use an open source platform, caution need to be given to the planning of time from the teacher, so that issues of burnout or overwhelming do not influence the quality of teaching. Strategies of joint administration of the page with the students could be considered if no additional support from teaching staff is at hand.

\section{References}

Garrison, D. R., \& Archer W. (2000). A transactional perspective on teaching and learning: a framework for adults and higher education. Oxford: Pergamon.

Garrison, D. R., \& Richardson J. C. (2009). A constructivistic approach to online learning: the community of inquiry framework. In P. C. (ed.), Information technology and constructivism in higher education: progressive learning framework (pp. 43-57). Hershey PA: IGI Global.

Johnson, A. (2002). A short guide to action research. Needham Heights, MA: Allyn and Bacon.

Jonasssen, D., Mayes, T. \& MacHeese, R. (1993). A manifesto for a constructivist approach to uses of technology in higher education. In T. M. E Duffy, Designing Environments for Constructive Learning (pp. 231-247). Berlin: Springer.

Probable Quotes from History (Fall, 1978). MATYC Journal, Inc., Garden City, New York., 189.

Raina, K., \& Khatri, P. (2015). Faculty engagement in higher education: prospects and areas of research. On the Horizon, Vol. 23 Iss: 4. pp. $285-308$.

Vygotsky, L. S. (1929). The problem of the cultural development of the child II. Journal of Genetic Psychology, 36, 415-32. 